\title{
In-vitro and in-vivo studies of a cytotoxin from Campylobacter jejuni
}

\author{
T. PANG, P. Y. WONG, S. D. PUTHUCHEARY, K. SIHOTANG* and W. K. CHANG† \\ Departments of Medical Microbiology, "Biochemistry and † Surgery, Faculty of Medicine, University of Malaya, \\ 59100 Kuala Lumpur, Malaysia
}

\begin{abstract}
Summary. Studies were performed on a cytotoxin (CT) from human strains of Campylobacter jejuni isolated in Malaysia. CT was detected by cytopathic effect (CPE) on HeLa cells at titres from 8 to 32 , in culture filtrates from $14(48 \%)$ of 29 human isolates. The CPE correlated well with a quantitative ${ }^{51} \mathrm{Cr}$-release assay where a specific release of $54-68 \%$ was noted. CT production was lost after 5-7 subcultures. CT activity was also detected in $5(26 \%)$ of 19 faecal filtrates from which CTproducing isolates were subsequently obtained. The mol. wt of CT was estimated by Sephadex G-50 chromatography to be $>30000$. In a suckling-mouse assay, CT consistently failed to demonstrate fluid accumulation after intragastric inoculation of culture filtrate. The Removable Intestinal Tie Adult Rabbit Diarrhoea (RITARD) assay was also used. Rabbits given CT-producing strains of $C$. jejuni developed bacteraemia and severe watery mucus-containing diarrhoea for the duration of the experiment with death of some animals. Rabbits given CT non-producing strains had less severe disease and none died. Rabbits given partially-purified CT had diarrhoea for 3 days but none died.
\end{abstract}

\section{Introduction}

Campylobacter jejuni is a major cause of disease in man and animals, most commonly causing an acute gastroenteritis but sometimes more severe systemic disease. With rotavirus and enterotoxigenic Escherichia coli, it is one of the principal causes of acute diarrhoeal disease amongst young children in developing countries (Glass et al., 1983). Despite extensive documentation of human infections with this organism the pathogenic mechanisms remain unknown. Several potentially pathogenic properties have been identified: attachment and colonisation, invasiveness, and enterotoxin and cytotoxin production (Newell, 1984). Although current evidence indicates a key role for invasive capacity, enterotoxin and cytotoxin may account for some of the spectrum of symptoms seen with $C$. jejuni.

Few studies have been performed on virulence factors associated with $C$. jejuni isolated in developing countries. We have previously reported the existence of a cytotoxin detected in culture filtrates of Malaysian $C$. jejuni clinical isolates. This is probably protein in nature and produced cytopathic effects (CPE) in various human cell lines (Wong et al., 1983). We report here the results of further in

Received 10 Jan. 1986; revised version accepted 6 Jun. 1986. vitro and in vivo investigations of this cytotoxin which may help to elucidate its pathogenic role.

\section{Materials and methods}

\section{Isolation of Campylobacter jejuni}

A total of 29 isolates of $C$. jejuni was obtained from blood or stool cultures of patients with acute gastroenteritis or septicaemia admitted to the University Hospital, Kuala Lumpur. Strains were isolated by standard procedures and were confirmed as $C$. jejuni by standard biochemical tests. Most were biotyped by Dr M. B. Skirrow (Public Health Laboratory, Worcester).

\section{Cytotoxin assay}

Methods used for the preparation of cell-free culture filtrates containing cytotoxin, maintenance of cell lines, and assay for cytotoxic activity through development of cytopathic effects (CPE) have been described previously (Wong et al., 1983).

\section{${ }^{51}$ Cr-release assay}

Approximately $10^{7} \mathrm{HeLa}$ cells in $10 \mathrm{ml}$ of Eagle's Minimal Essential Medium (MEM) were labeled with $100 \mu \mathrm{Ci}$ of ${ }^{51} \mathrm{Cr}$ (sodium chromate; Amersham International, UK) for $1 \mathrm{~h}$ at $37^{\circ} \mathrm{C}$. Cells were then washed three 
times with MEM and adjusted to a concentration of $2 \times$ $10^{5}$ cells $/ \mathrm{ml}$ in MEM with $5 \%$ fetal calf serum (FCS); $100 \mu \mathrm{l}$ of this suspension was added to flat-bottomed wells of microtitration plates. To each well, $100 \mu \mathrm{l}$ of a 1 in 8 dilution of culture filtrate was then added and the plates were incubated at $37^{\circ} \mathrm{C}$ for $48 \mathrm{~h}$ in $5-10 \% \mathrm{CO}_{2}$. Distilled water and Eagle's MEM (with $5 \%$ FCS) respectively, were added to the wells as controls for maximal $(100 \%)$ and spontaneous ${ }^{51} \mathrm{Cr}$ release. Another control group was included when nutrient broth was added to the labeled cells. After the incubation period the supernate was carefully removed from each well without disturbing the cells at the bottom and was transferred to a counting vial. Cells were lysed by adding $0.2 \mathrm{ml}$ of distilled water and the lysates were removed to separate counting vials. Radioactivity was measured in a $\gamma$ counter. The percentage of ${ }^{51} \mathrm{Cr}$ released from target cells in each well was calculated by the formula:

$$
\frac{\text { Counts in supernate }}{\text { Counts in supernate }+ \text { counts in cells }} \times 100
$$

\section{Cytotoxicity testing of stool filtrates}

Equal volumes of the stool specimens and phosphate-

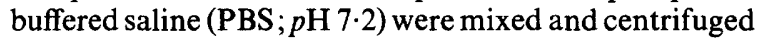
at $3000 \mathrm{~g}$ for $30 \mathrm{~min}$. The supernate was then filtered through a $0.22-\mu \mathrm{m}$ membrane filter (Millipore Corp., USA) and two-fold serial dilutions were made in MEM with $5 \%$ FCS. These were then inoculated on to HeLa cell monolayers which were scanned for cytopathic effects. Serial passage of the tissue culture material was also performed to exclude a viral cause of observed cytotoxic activity.

\section{Sephadex G-50 chromatography of culture filtrate}

A 300-ml volume of CT-containing culture filtrate was freeze-dried and the resultant $20 \mathrm{mg}$ of protein dissolved in $20 \mathrm{ml}$ of distilled water. This was loaded on a $30 \mathrm{~cm} \times$ $2.2 \mathrm{~cm}$ Sephadex G-50 column (Pharmacia Fine Chemicals, Sweden) and eluted at $4^{\circ} \mathrm{C}$ with $50 \mathrm{~mm}$ Trishydroxymethylamine- $\mathrm{HCl}$ buffer $(p \mathrm{H} 7.5)$ (Sigma Chemical Co., USA). The estimated flow rate was $120 \mathrm{ml} / \mathrm{h}$. Protein content of eluted fractions was determined by spectrophotometry at $280 \mathrm{~nm}$; pooled fractions were concentrated by freeze-drying and were then dissolved in

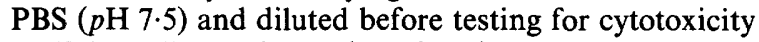
on HeLa cell monolayers (see above).

\section{Suckling mouse assay}

The assay used was a modification of the method of Dean et al. (1972) (Giannella 1976); $100 \mu$ l of sterile culture filtrate containing one drop of $2 \%$ Evans Blue dye was administered intragastrically via a fine polyethylene tube (external diameter $0.6 \mathrm{~mm}$ ) connected to a $1-\mathrm{ml}$ syringe. Four suckling mice (1-3 days old) were used for each group. Control mice were given sterile nutrient broth and a positive control was set up in which mice were given heat-stable toxin (ST) from an enterotoxigenic strain of Escherichia coli (strain 027-H7). After inoculation mice were placed on filter paper and kept for $4 \mathrm{~h}$ at $28^{\circ} \mathrm{C}$ and were then killed by cervical dislocation and the intestines collected. Intestines from each group of four mice were pooled and weighed. The ratio of intestinal weight to remaining body weight was calculated (IW:BW ratio). A ratio of 0.08 or greater was considered to indicate a positive response. Animals with no dye in the intestines or with dye within the peritoneal cavity at autopsy, and those which regurgitated during the inoculation procedure were discarded.

\section{RITARD procedure}

Surgical procedures used were as described previously by Spira et al. (1981). Rabbits were anaesthetised with sodium pentobarbitone (Abbott Laboratories, Australia) and the abdomen opened. The caecum and ileum were brought out through a midline incision and ligated near the ileocaecal junction with sterile obstetric tape and a slip knot was used to ligate gently the terminal ileum immediately anterior to the mesoappendix. A $10-\mathrm{ml}$ inoculum of $C$. jejuni broth culture or filtrate was injected into the lumen of the anterior jejunum, and the intestine and caecum were returned to the peritoneal cavity. The incision was then closed and the loose ends of the slip knot brought out through the incision. Four hours after surgery the slip knot was released gently thus releasing the inoculum. Following release of the knot, animals were given food and water ad libitum and were observed for overt diarrhoea, signs of weakness, and death. Rectal swabs were taken daily for 2 weeks to monitor shedding of the inoculated organisms. Blood was collected aseptically from the outer marginal ear vein daily for the initial 4 postoperative days. It was inoculated in to Robertson's Cooked Meat Medium and subsequently processed for C. jejuni isolation (see above).

\section{Statistical analysis}

Results obtained from the suckling-mouse assays and ${ }^{51} \mathrm{Cr}$-release test are expressed as arithmetic mean $\pm \mathrm{SD}$ from the mean for groups of four.

\section{Results}

Of the 29 strains of $C$. jejuni tested for cytotoxin (CT) production, $14(48 \%)$ were positive to a titre of at least 8 , as shown by CPE on HeLa, Hep- 2 and MRC-5 cell lines. No CPE was detected with animal cell lines of monkey (Vero cells) and mouse (L-929 fibroblasts) origin. An attempt to quantitate the observed CPE by a ${ }^{51} \mathrm{Cr}$-release assay showed that a specific release of $54-68 \%$ of label was obtained with CT-containing culture filtrates that produced CPE on HeLa cells (table I). Culture filtrates that did not produce CPE caused negligible release of label. Furthermore, CT activity was also detected in faecal specimens from patients with 
Table I. Relationship between CPE on HeLa cells and release of ${ }^{51} \mathrm{Cr}$

\begin{tabular}{lcc}
\hline $\begin{array}{l}\text { C. jejuni } \\
\text { isolate* }\end{array}$ & $\begin{array}{c}\text { CPE } \\
\text { after } 48 \mathrm{~h}\end{array}$ & $\begin{array}{c}\text { Percentage }{ }^{51} \mathrm{Cr} \text { release from } \\
\text { HeLa cells } \dagger\end{array}$ \\
\hline 8480 & + & $58 \pm 1$ \\
7001 & + & $68 \pm 2$ \\
2584 & + & $68 \pm 2$ \\
3936 & + & $62 \pm 1$ \\
4093 & + & $54 \pm 1$ \\
4856 & - & $25 \pm 2$ \\
3271 & - & $29 \pm 2$ \\
2101 & - & $12 \pm 3$ \\
2690 & - & $14 \pm 2$ \\
Broth & - & $22 \pm 0 \cdot 5$ \\
Culture & - & $11 \pm 2$ \\
medium & - & $88 \pm 1$ \\
Water & - & \\
\hline
\end{tabular}

${ }^{*}$ Culture filtrates were tested at a dilution of 1 in 8 ; culture medium was Eagle's MEM with $5 \%$ FCS.

† Values represent mean ( \pm SD from the mean) of results from four wells.

gastro-intestinal disease from which $C$. jejuni was isolated as the sole pathogen; of the 19 specimens tested, five $(26 \%)$ caused CPE on HeLa cells (table II). Titres were in the range 8 to 32 (table II). Two specimens produced CPE that could be serially passaged and that could not be demonstrated with the culture filtrate (table II). A further 18 filtrates of faecal samples that gave positive results in tests for other pathogens (enteropathogenic $E$. coli, Salmonella or Shigella spp.) produced no CPE (data not shown). CT-producing capacity diminished with repeated subculture. This was seen in the three isolates tested (table III). By the eighth subpassage, all three strains failed to produce any detectable CPE. Analysis of the CT-containing culture filtrate concentrated by freeze-drying was performed with Sephadex G-50 columns, which retained molecules of mol. wt 3500-30 000. CT activity was associated with the third protein peak (P3) giving an estimated mol. wt $>30000$ (figure). In-vivo CT activity was assessed in two experimental systems. Most of the IW : BW ratios in suckling mice were $<0.06$ for $C$. jejuni strains tested, regardless of CT production. These results were highly reproducible in at least three separate experiments with errors within +0.006 (table IV). The RITARD procedure was also used. All rectal swabs from infected animals gave positive results $24 \mathrm{~h}$ after inoculation of $C$. jejuni (table V) and the organisms continued to be shed for 2 weeks. Blood cultures positive for $C$. jejuni were obtained from four of five rabbits given a CT-positive strain of $C$. jejuni $24 \mathrm{~h}$ earlier (table $\mathrm{V})$, as well as from two of five animals given a CT-
Table II. Detection of cytotoxicity in filtrates of faecal specimens from which $C$. jejuni was isolated

\begin{tabular}{lcc}
\hline & \multicolumn{2}{c}{ CPE observed with } \\
\cline { 2 - 3 } $\begin{array}{l}\text { C. jejuni } \\
\text { isolate }\end{array}$ & faecal filtrate* & culture filtrate $\dagger$ \\
\hline 7700 & $+(16)$ & + \\
5665 & $+(16)$ & + \\
8405 & $+(8)$ & + \\
9366 & $+(32)$ & + \\
1927 & $+(16)$ & + \\
2968 & $+\ddagger$ & - \\
3890 & $+\ddagger$ & - \\
12 others & - & -
\end{tabular}

* Numbers in parentheses are the highest dilutions at which CPE was observed after $48 \mathrm{~h}$.

$\uparrow$ Culture filtrate assayed at a dilution of 1 in 8 .

$\ddagger$ CPE could be serially passaged.

negative strain. Bacteraemia decreased gradually over a 4-day period with the CT-positive strain but organisms could not be isolated from the second day onwards from the blood of those animals given the CT-negative strain. All five rabbits given the CT-positive strain of $C$. jejuni developed diarrhoea which lasted for 4-5 days. The animals showed signs of weakness, and two died after 4 and 6 days respectively. In contrast, diarrhoea of shorter duration (2-3 days), with no subsequent deaths, was observed in two of the five rabbits given the CT-negative strain. Three out of the five rabbits given CT alone (ammonium sulphate-precipitated culture filtrate) also developed significant diarrhoea for about 3 days; no deaths occurred in this group of animals.

Table III. Effect of in-vitro subculture of $C$. jejuni on cytotoxicity

\begin{tabular}{crcc}
\hline & \multicolumn{3}{c}{$\begin{array}{c}\text { Cytotoxic titre of culture filtrate from } C . \\
\text { jejuni isolates* }\end{array}$} \\
\cline { 2 - 4 } $\begin{array}{c}\text { Number of } \\
\text { subcultures }\end{array}$ & 3936 & 2584 & 7001 \\
\hline 1 & 32 & 16 & 32 \\
2 & 32 & 16 & 32 \\
3 & 32 & 8 & 32 \\
4 & 16 & 8 & 16 \\
5 & 8 & - & 16 \\
6 & 8 & - & 8 \\
7 & - & - & 8 \\
8 & - & - & - \\
9 & - & - & -
\end{tabular}

* Highest dilution of culture filtrate that caused rounding of $>50 \%$ of HeLa cells; - indicates no CPE. 


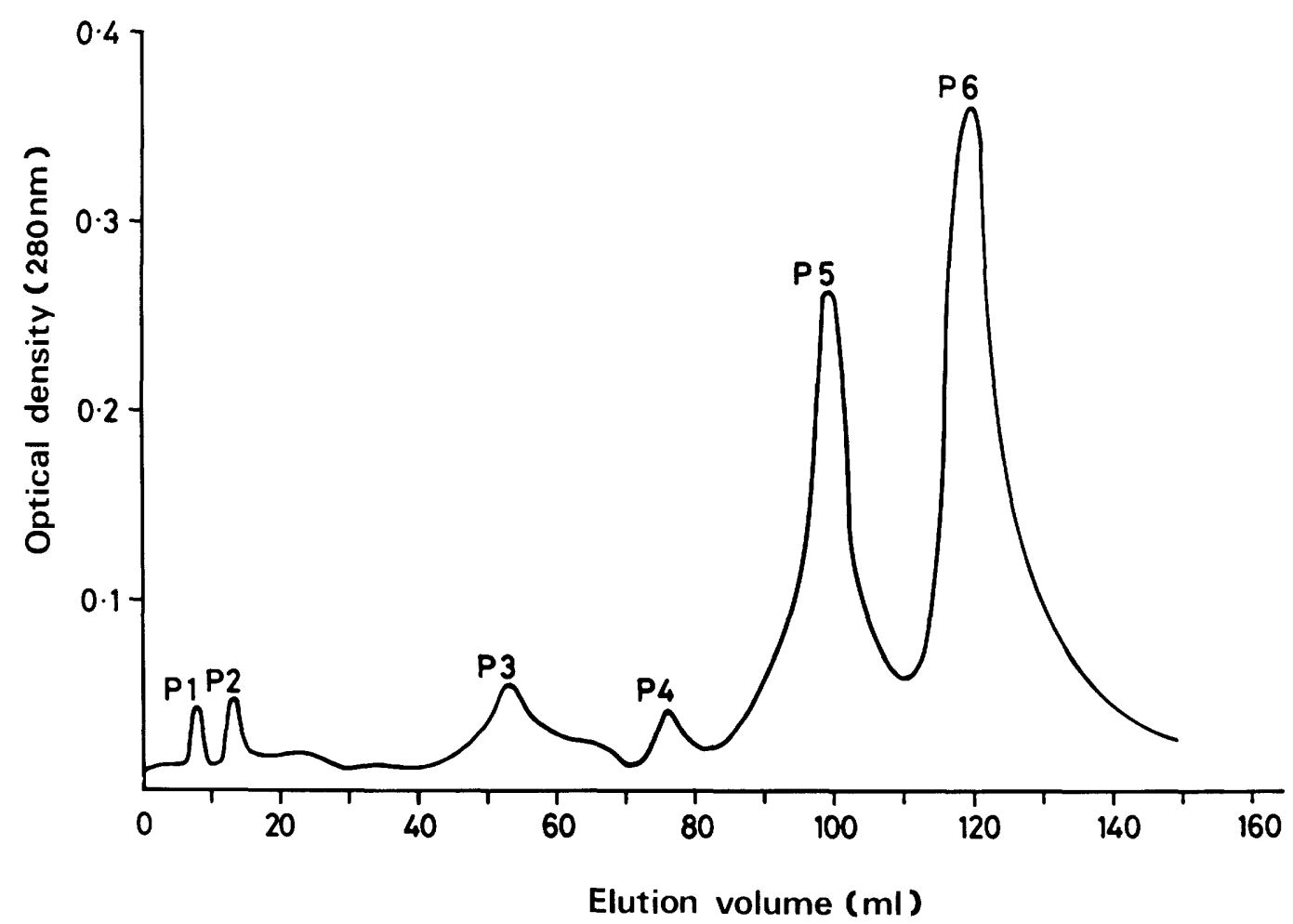

Figure Chromatographic training of freeze dried $C$. jejuni $C T$ on a Sephadex G-50 column. $P=$ protein peak. Cytotoxic activity was associated with fraction $\mathbf{P} 3$.

\section{Discussion}

The present study has further characterised the cytotoxin (CT) obtained from Malaysian isolates of C. jejuni. A previous report stated that toxinproducing strains are uncommon in Asia (Wadström et al., 1983). Another report (Johnson and Lior, 1984) suggests that CT-producing strains are quite common amongst human isolates of $C$. jejuni. We detected a total of $14(48 \%)$ CT-producing strains amongst 29 clinical isolates in the present study. Characterisation of the CT indicated that it has a mol. wt $>30000$, which is consistent with a previous study that demonstrated the mol. wt to be $>100000$ (Newell, 1984).

The present study also showed CT-producing ability to be lost on repeated subculture. One explanation of this could be that $\mathrm{CT}$ production is mediated by plasmid(s). Enterotoxin production by $E$. coli is plasmid-mediated (Gyles et al., 1974) and a similar proposal has been made previously for cytotoxicity of $C$. jejuni (Taylor et al., 1981; Bradbury et al., 1983).

The cytopathic effect correlated well with signif- icant release of ${ }^{51} \mathrm{Cr}$ from labeled HeLa cells. This suggests that the CT of $C$. jejuni affects membrane integrity leading to cell death and release of ${ }^{51} \mathrm{Cr}$ into the supernate. Previous studies have suggested that ${ }^{51} \mathrm{Cr}$ is probably bound to cell organelles and organic cations, thus the label would be released upon cell death (McBride, 1978). This mechanism is characteristic of many cytolytic toxins such as those of Staphylococcus (Thelestam \& Bronnegard, 1980 ) and Cl. difficile (Donta and Shaffer, 1980).

The present study also confirmed that CT activity could be detected in faecal filtrates obtained from patients from whom $C$. jejuni was the only pathogen isolated. This is in agreement with the finding of CT activity in $67 \%$ of stool filtrates by Johnson and Lior (1984). In two faecal filtrates tested in the present study, CPE continued to be produced with serial passage of the culture medium on to fresh HeLa cells. It is likely that a virus was involved.

The significance of CT production by $C$. jejuni is unclear (Newell, 1984; Klipstein et al., 1985). The suckling mouse assay showed that all strains of $C$. jejuni tested, regardless of CT production, had no enterotoxic activity, a finding that agrees with the 
Table IV. Testing of enterotoxicity of $C$. jejuni isolates by the suckling mouse assay

\begin{tabular}{lcc}
$\begin{array}{l}\text { C. jejuni } \\
\text { isolate }\end{array}$ & CPE on HeLa cells & IW:BW ratio \\
\hline 7001 & + & $0.069 \pm 0.016$ \\
3584 & + & $0.047 \pm 0.005$ \\
3936 & + & $0.049 \pm 0.010$ \\
8480 & + & $0.055 \pm 0.007$ \\
4093 & + & $0.065 \pm 0.007$ \\
2687 & + & $0.057 \pm 0.002$ \\
3217 & + & $0.045 \pm 0.001$ \\
4856 & - & $0.048 \pm 0.007$ \\
2690 & - & $0.052 \pm 0.002$ \\
3271 & - & $0.055 \pm 0.004$ \\
2101 & - & $0.061 \pm 0.005$ \\
Broth & - & $0.041 \pm 0.002$ \\
E. coli $\mathrm{ST}$ & $\mathrm{NT}$ & $0.091 \pm 0.003$ \\
& & \\
\hline
\end{tabular}

IW : BW ratio = intestinal weight:body weight ratio. Figures represent means \pm SEM for four mice. NT $=$ not tested.

results of previous studies (Guerrant et al., 1978; Ruiz-Palacios et al., 1983; Johnson and Lior, 1984) and further supports the general consensus on the absence of ST-like enterotoxin production by $C$. jejuni. Similarly, other studies showed that CT from $C$. jejuni did not induce fluid secretion in rat ligated ileal loops (Klipstein et al., 1985). The RITARD procedure was initially developed by Spira et al. (1981) and adapted for $C$. jejuni by Caldwell et al. (1983) who noted a diarrhoeal attack rate of $64 \%$ and intestinal histopathology similar to that of campylobacter enteritis in man. The present study clearly showed that diarrhoea induced by CTpositive strains was more severe than that caused by CT-negative strains, sometimes even resulting in death of rabbits. The diarrhoea induced by the CT-negative strain 2690 (table V) was probably not due to the production of extracellular cytotoxin but may have been related to enteroinvasiveness of this particular isolate; the patient from whom this strain was isolated had repeated, blood-streaked, stools during the course of his illness. Bacteraemia also lasted longer in rabbits given CT-positive strains. Moreover, inoculation of concentrated CT alone consistently produced diarrhoea in rabbits, in contrast to the transient loose stools in controls given broth or in animals given concentrated culture filtrate from CT-negative strains. This suggests a role for CT in producing diarrhoea. Although no conclusions could be formed about the mechanism(s) involved, a recent study by Klipstein et al. (1985) found that all $C$. jejuni isolates from persons with bloody diarrhoea produced a cytotoxin and showed evidence of invasive properties. This could indicate that $\mathrm{CT}$ plays a role in the invasion of the intestinal mucosa, which is compatible with the occurrence of bloody diarrhoea. Klipstein et al. (1985) also concluded that the CT from $C$. jejuni had no pathophysiological significance because titres of CT were low (which we also noted) and because the CT did not induce fluid secretion in ligated ileal loops. However, in view of our findings that CT alone consistently produced diarrhoea in rabbits, and the observation by Klipstein et al. (1985) that CT production was closely associated with invasiveness, we feel it is premature to discount CT from playing any role in disease pathogenesis.

Table V. Response of rabbits to intraluminal challenge with whole cells or culture filtrates of $C$. jejuni

Number of rabbits that developed

\begin{tabular}{lcccccc}
\cline { 4 - 6 } Inoculum & $\begin{array}{c}\text { Number of } \\
\text { rabbits }\end{array}$ & Bacteraemia & Diarrhoea & $\begin{array}{c}\text { Diarrhoea, } \\
\text { then died }\end{array}$ & $\begin{array}{c}\text { Positive } \\
\text { rectal culture }\end{array}$ & $\begin{array}{c}\text { No } \\
\text { symptoms }\end{array}$ \\
\hline $\begin{array}{l}\text { Nutrient broth } \\
\text { Whole cell* }\end{array}$ & 5 & 0 & $0 \ddagger$ & 0 & 0 & 5 \\
$\quad \begin{array}{l}2584(+) \\
2690(-)\end{array}$ & 5 & 4 & 3 & 2 & 5 & 0 \\
$\begin{array}{l}\text { Culture filtrate } \dagger \\
2584(+)\end{array}$ & 5 & 2 & 2 & 0 & 5 & 3 \\
$2690(-)$ & 5 & 0 & 3 & 0 & 0 & 2 \\
\hline
\end{tabular}

$(+)=\mathrm{CT}$-positive strain; $(-)=\mathrm{CT}$-negative strain.

*c. $1.4 \times 10^{8} \mathrm{cfu} / \mathrm{ml}$.

+ Concentrated by ammonium sulphate precipitation.

$\ddagger$ Transient loose stools $24 \mathrm{~h}$ after inoculation. 
Indeed Newell (1984) has pointed out that although invasiveness appears to be central to pathogenesis, CT may account for the spectrum of symptoms seen in C. jejuni infections. For example, CT may have enzymic activity that destroys cell membranes allowing penetration through the intestinal mucosa (Ruiz-Palacios et al., 1981). It is evident that further investigations, perhaps with highly purified CT in the rabbit model, are warranted.

This work was supported by University of Malaya $F$ Vote Grant No. F 59/83 and China Medical Board Grant No. 78374.

\section{REFERENCES}

Bradbury W C, Marko M A, Hennessy J N, Penner J L 1983 Occurrence of plasmid DNA in serologically defined strains of Campylobacter jejuni and Campylobacter coli. Infection and Immunity 40:460-463.

Caldwell M B, Walker R I, Stewart S D, Rogers J E 1983 Simple adult rabbit model for Campylobacter jejuni enteritis. Infection and Immunity 42:1176-1182.

Dean A G, Ching Y C, Williams R G, Harden L B 1972 Test for Escherichia coli enterotoxin using infant mice: application in a study of diarrhea in children in Honolulu. Journal of Infectious Diseases 125:407-411.

Donta S T, Shaffer S J 1980 Effects of Clostridium difficile toxin on tissue-cultured cells. Journal of Infectious Diseases $141: 218-222$.

Giannella R A 1976 Suckling mouse model for detection of heatstable Escherichia coli enterotoxin: characteristics of the model. Infection and Immunity 14:95-99.

Glass R I, Stoll B J, Huq M I, Struelens M J, Blaser M, Kibriya A K M G 1983 Epidemiologic and clinical features of endemic Campylobacter jejuni infection in Bangladesh. Journal of Infectious Diseases 148:292-296.

Guerrant R L, Lahita R G, Winn W C, Roberts R B 1978 Campylobacteriosis in man: pathogenic mechanisms and review of 91 bloodstream infections. American Journal of Medicine 65: 584-592.

Gyles C, So M, Falkow S 1974 The enterotoxin plasmids of Escherichia coli. Journal of Infectious Diseases 130:40-49.

Johnson W M, Lior H 1984 Toxins produced by Campylobacter jejuni and Campylobacter coli. Lancet 1:229-230.

Klipstein F A, Engert R F, Short H, Schenk E A 1985 Pathogenic properties of Campylobacter jejuni: assay and correlation with clinical manifestations. Infection and Immunity 50:4349.

McBride W H 1978 Notes on the use of in vitro techniques for the assessment of cellular reactivity against tumours. In: Weir D M (ed) Handbook of experimental immunology, 3rd edn. Blackwell Scientific Publications, Oxford, pp. 36.1-36.14.

Newell D G 1984 Experimental studies of campylobacter enteritis. In: Butzler J P (ed) Campylobacter infection in man and animals. CRC Press Incorporated, Boca Raton, pp 113-131.

Ruiz-Palacios G M, Escamilla E, Torres N 1981 Experimental Campylobacter diarrhoea in chickens. Infection and Immunity 34:250-255.

Ruiz-Palacios G M, Torres N I, Ruiz-Palacios B, Torres J, Escamilla E, Tamayo J 1983 Cholera-like enterotoxin produced by Campylobacter jejuni: characterisation and clinical significance. Lancet 2:250-253.

Spira W M, Sack R B, Froehlich J L 1981 Simple adult rabbit model for Vibrio cholerae and enterotoxigenic Escherichia coli diarrhea. Infection and Immunity 32:739-747.

Taylor D E, DeGrandis S A, Karmali M A, Fleming P C 1981 Transmissible plasmids from Campylobacter jejuni. Antimicrobial Agents and Chemotherapy 19:831-835.

Thelestam M, Bronnegard M 1980 Interaction of cytopathogenic toxin from Clostridium difficile with cells in tissue culture. Scandinavian Journal of Infectious Diseases 22 Suppl : 16-29.

Wadström T, Baloda S B, Krovacek K, Faris A, Bengtson S, Walder M 1983 Swedish isolates of Campylobacter jejunil coli do not produce cytotonic or cytotoxic enterotoxins. Lancet 2:911.

Wong P Y, Puthucheary S D, Pang T 1983 Demonstration of a cytotoxin from Campylobacter jejuni. Journal of Clinical Pathology 36: 1237-1240. 